\title{
Magnitude and Sources of Intra-clonal Variation in 'Foster' Holly
}

\author{
Cecil T. Pounders \\ Department of Plant and Soil Science, Alabama A \& M University, Normal, AL 35762 \\ G. Sam Foster \\ U.S. Department of Agriculture Forest Service, Southern Forest Experiment Station, Alabama A \& M \\ University, Normal, AL 35762
}

Additional index words. periphysis, Ilex $\times$ attenuata, maturation, propagation, stock plant, clone

\begin{abstract}
A statistical model was used to partition the effects of age group, cutting position within the plant crown, and ramet environment on propagule development from stem cuttings collected from random stock plants of Ilex $\times$ attenuata Ashe 'Foster \#2' ('Foster' holly). Most of the intra-clonal variation observed originated from sources not partitioned by the model. Small differences in growth were associated with sampling position within the crown. Repropagation gave no indication that factors measured by the model could be passed from ramet to propagule. Within-clone variation was not reduced by repropagation or by hedging propagules to force new growth.
\end{abstract}

The common assumption that propagules of a cultivar are genetically identical and therefore should grow alike is misleading (Blake and Filho, 1988). Clonal variation results when cuttings are taken from different parts of the stock plant or when ramets of a clone are subjected to different environmental conditions or cultural treatments (Zobel and Talbert, 1984). Environmental effects common to members of a group of relatives were defined by Lerner (1958) as "C" effects. Other researchers expanded the definition of $\mathrm{C}$ effects to include environmental factors that persist in clones for various lengths of time, resulting in increased variance among clones (Cannell et al., 1978; Foster et al., 1984; Libby and Jund, 1962). Burdon and Shelbourne (1974) defined two types of maternal effects in plants as "M" and "m". The nongenetic changes that occur within all members of a clone and increase inter-clone variance are classified as $\mathrm{M}$ effects, which are synonymous with $\mathrm{C}$ effects. Such changes do not add to variation within a clone, but change the clone mean. The maternal effects unique to a ramet and its propagules are termed $m$ effects and add to intra-clonal variance, creating what is generally defined as epigenetic variation (Kester, 1983).

Part of the intra-clonal variance within woody-plant clones is associated with maturation and aging (Hackett, 1983). Plant development is often classified into juvenile, mature, and senescent phases. Progressive changes in morphological and metabolic characteristics are associated with these phase changes, but changes in some traits, such as vigor and branching habit, may be continuous across phases and vary between species (Hackett, 1985).

Changes directly associated with maturation are stable, but such changes are confounded by physiological interactions that can be manipulated (Wareing, 1959). Cuttings from the second or subsequent propagation cycles of Japanese red pine (Pinus densiflora Sieb. and Zucc.) and Douglas fir [Pseudotsuga menziesii (Mirb.) Franco] rooted more readily or had more vigor than firstcycle cuttings (Black, 1972; Ooyama and Toyoshima, 1965). Serial propagation reduced plagiotropic growth associated with aging in coast redwood [Sequoia semperivirens (D. Don) Endl.] (Boulay, 1979). Environmental factors, such as mineral nutrition,

Received for publication 9 June 1992. Accepted for publication 29 June 1993. The cost of publishing this paper was defrayed in part by the payment of page charges. Under postal regulations, this paper therefore must be hereby marked advertisement solely to indicate this fact. pruning, and temperature, that increased root activity and stem vigor of stock plants resulted in better rooting and more favorable growth orientation of propagules (Franclet, 1979).

Mature characteristics first appear in the upper and peripheral parts of a plant (Olesen, 1978). The terminal growth is chronologically the youngest but ontogenetically the most mature, since it results from more mitotic divisions of the meristematic initials (Franclet, 1983). This pattern of maturation within the crown of woody plants affects rooting potential (Roulund, 1973), leaf shape (Ashby, 1949), plant form (Roulund, 1979), thorniness (Soost and Cameron, 1975), and leaf retention (Schaffalitzkey de Muckadell, 1959). Some researchers recognized the production ramifications of these maturation-related changes within clones and developed methods to stabilize or restrain intra-clonal variation (Libby, 1974; Libby and Hood, 1976).

Ilex $\times$ attenuata 'Foster \#2' ('Foster' holly) is a clone that has been produced by nurserymen in the southern United States and Europe since its selection in the late 1940s (Galle, 1970). It is one of the most variable clones produced by growers with respect to branching structure and plagiotropic growth as a young plant. Ramets were available that varied in age and maintenance practices such as fertilization and pruning. Therefore, this clone was chosen as a good model to study the effects of intra-clonal variation of a commonly produced woody ornamental. The three objectives of this study were to 1) evaluate the effects of ramet age and cutting position within the plant crown on propagule development and plagiotropic growth, 2) determine if pruning liners and secondary propagation affect stability of intra-clonal variation, and 3) test the relationships between six growth indexes and their sensitivity to epigenetic changes.

\section{Materials and Methods}

Twenty-four 'Foster' holly plants were randomly selected to sample the available sizes (e.g., 0.6 to $7.2 \mathrm{~m}$ high) growing in commercial and residential landscapes in Huntsville and Decatur, Ala. Selected plants were judged to be healthy by leaf color and the production of sufficient new growth for cuttings. All plants had a full canopy from ground level and had been pruned at various times during their development. The selections ranged from 2 to 28 years old, as estimated by counting annual growth rings in cores taken 10 $\mathrm{cm}$ above ground level. Ramets were arbitrarily subgrouped by 
age, with plants 2 to 6 years old in group 1, plants 9 to 16 years old in group 2, and plants 18 to 28 years old in group 3 (Table 1).

Each plant was vertically divided into bands for sampling cuttings. Trends of trait performance provide a measure of maturation-induced changes within the crown of the plant. On 3 July 1989 , cuttings were randomly collected within horizontal $60-\mathrm{cm}$ vertical swaths around the circumference of the crown (a band). The number of bands within a ramet was determined by tree height, and bands were numbered beginning at the band from ground level to $60 \mathrm{~cm}$ (band 1) and were contiguous, continuing up the entire crown (Fig. 1). Twenty $4.5-\mathrm{cm}$ terminal cuttings of uniform diameter (3 to $6 \mathrm{~mm}$ ) were randomly taken from each band. Bottom leaves were stripped from each cutting, each of which retained only three to five terminal leaves. Cuttings were then dipped (1.5 $\mathrm{cm}$ ) for $5 \mathrm{sec}$ in a $12.3 \mathrm{~mm}(2500 \mathrm{ppm}) 1 \mathrm{H}$-indole-3-butyric (IBA) acid solution ( $2.5 \mathrm{~g}$ IBA dissolved in $250 \mathrm{ml} 70 \%$ isopropanol plus $750 \mathrm{ml}$ distilled water) and inserted $(2 \mathrm{~cm})$ into a medium of 1 Canadian peat moss : 1 coarse perlite (v/v) in unitized trays (93$\mathrm{cm}^{3}$ cell) (Hiko; International Forest Seed Co.; Odenville, Ala.).

To assess the persistence of intra-clonal differences in growth and morphology, material was serially propagated (cycled) twice. In addition, shoots were allowed to develop for one growing season (phase 1), after which the new growth was removed and the plants were allowed to regrow (phase 2) (Fig. 1). Cycle 1, phase 1 (Fig. 1) began when trays were placed in a shaded (55\% transmittance) greenhouse in which cuttings were misted daily for $15 \mathrm{sec}$ every 15 min from 8 AM to 5 PM on sunny days. Mist was manually applied as needed on cloudy days. By 7 Aug. 1989 (5 weeks), most cuttings had rooted and misting was discontinued. Thereafter, plants were drenched weekly with $175 \mathrm{ppm} \mathrm{N}$ from a 20N-9P-16K water-soluble fertilizer (Peters Fertilizer Co.; Fogelville, Pa.). Cool-white fluorescent lamps were used to extend daylength to 14 $\mathrm{h}$. Minimum air temperature was $18 \mathrm{C}$ until the first set of measurements was made.

Plants remained in propagation trays until 15 Sept. 1989, when most plants had achieved sufficient shoot growth to shade neighboring plants. Plants and the medium in the cells were transplanted into $10-\mathrm{cm}\left(515-\mathrm{cm}^{3}\right)$ square pots containing the same medium used for propagation, and plants were allowed to grow until $10 \mathrm{Jan}$. 1990 (6 months), when data were collected on each plant's development. Measurements included the angle of the dominant shoot (ANG) measured with a protractor to the nearest $10^{\circ}$ from the vertical, length $(\mathrm{cm})$ of the dominant shoot $(\mathrm{HT})$, sum of lengths $(\mathrm{cm})$ of all shoots (TSL), total number of shoots (SHN), number of nodes on the dominant shoot (NDS), and percentage of unserrated leaves (a possible maturation index) on the dominant shoot (PUL). After data were collected, terminal cuttings were severed from the dominant shoots of each plant for propagules in cycle 2 .

Cycle 1, phase 2 (Fig. 1) began when all shoots of each plant were pruned back to two nodes above the original cutting. After pruning, plants were allowed to go dormant for $\approx 2$ months by discontinuing fertilization and supplemental artificial lighting while subjecting the material to seasonal temperature fluctuations. A minimum temperature of $2 \mathrm{C}$ was maintained, however, to prevent freeze injury. Growth resumed under natural conditions in early March, when the minimum temperature was raised to $18 \mathrm{C}$ and weekly fertilization was resumed. Plants grew until 8 Aug. 1990 (6 months), when regrowth was measured using the same parameters as in cycle 1 , phase 1 .

Cycle 2, phase 1 (Fig. 1) began with terminal cuttings collected from the dominant shoot of each plant at the end of cycle 1, phase 1 on 15 Jan. 1990. Cuttings were prepared and propagated using the same procedures outlined for cycle 1 . The numbering system
Table 1. Characterization of 24 'Foster' holly ramets selected at random.

\begin{tabular}{lccc}
\hline \hline Age group & $\begin{array}{c}\text { Age range } \\
\text { (years) }\end{array}$ & $\begin{array}{c}\text { Ramets } \\
\text { (no.) }\end{array}$ & $\begin{array}{c}\mathrm{Bands}^{\mathrm{z}} \\
\text { (no.) }\end{array}$ \\
\hline 1 & $2-6$ & 6 & 7 \\
2 & $9-16$ & 12 & 55 \\
3 & $18-28$ & 6 & $49^{\mathrm{y}}$ \\
\hline
\end{tabular}

${ }^{\mathrm{z}}$ Total number of 60 -cm bands for all ramets in each age group.

${ }^{\mathrm{y}}$ Alternate bands were retained for growth studies in the tops of tallest ramets to maintain test limit of 100 bands.

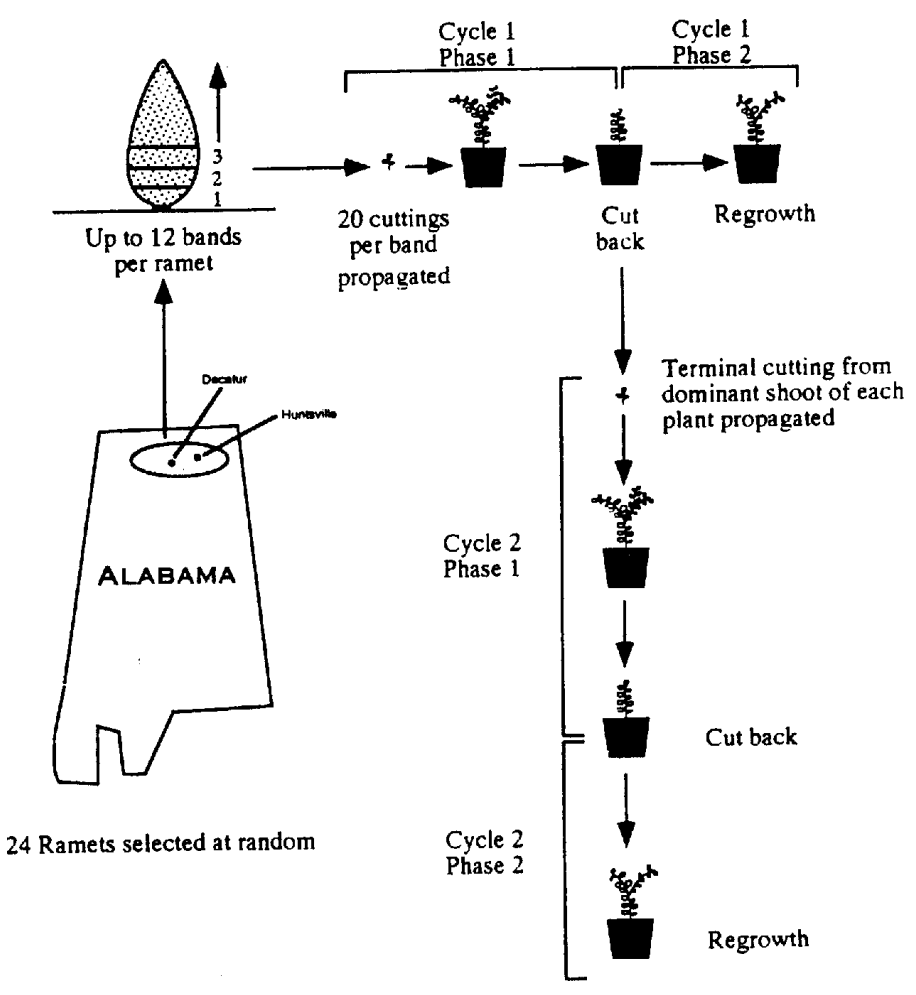

Fig.1. Cloning process of 'Foster' holly to determine magnitude of intra-clonal variation due to ramet and cutting position.

and experimental design were identical in cycles 1 and 2 so that direct comparisons could be made between a ramet in cycle 1 and its propagule in cycle 2 . Cuttings rooted by 30 Mar. 1990 (10 weeks), when mist was discontinued and weekly fertilization started. By 15 Aug. 1990, plants were becoming crowded in propagation trays and were transplanted into $10-\mathrm{cm}$ square pots as in cycle 1 . The photoperiod was adjusted to $14 \mathrm{~h}$ and minimum air temperature was maintained at $18 \mathrm{C}$ as in cycle 1 .

On 1 June 1991, plants appeared to be equal in size to those in cycle 1 , phase 1 , when measurements of the standard six growth indexes were collected.

Cycle 2, phase 2(Fig. 1) commenced after data collection, when all shoots of each plant in cycle 2 , phase 1 were removed back to two nodes above the original cutting. Shoot regeneration was rapid and, on 5 Sept. 1991, data for the six growth indexes were collected.

The experimental design throughout the study was a randomized complete block with four blocks. Each plot consisted of a row of five cuttings from one band of a ramet. The form of analysis is presented in Table 2. Blocks, age, plants (age), and bands were considered to be random effects, while cycles and phases (cycle) 
Table 2. Form of the analysis of variance for six growth indexes of 'Foster' holly.

\begin{tabular}{|c|c|c|}
\hline Source & df & Expected mean squares \\
\hline$\overline{\text { Cycle }(\mathrm{C})}$ & 1 & $\sigma_{2}+$ hbro $\sigma_{\mathrm{CP}(\mathrm{A})}^{2}+\mathrm{hbpr}_{\mathrm{CA}}{ }^{2}+$ hbapr $\theta_{\mathrm{c}}$ \\
\hline Phase $(\mathrm{H}) / \mathrm{C}$ & 2 & $\sigma^{2}+b r \sigma_{\mathrm{H}(\mathrm{C}) \mathrm{P}(\mathrm{A})}{ }^{2}+\mathrm{brp} \sigma_{\mathrm{AH}(\mathrm{C})}{ }^{2}+a p r \sigma_{\mathrm{bh}(\mathrm{C})}{ }^{2}+$ bapr $\theta_{\mathrm{H}(\mathrm{C})}$ \\
\hline Age group $(\mathrm{A}$ & ) 2 & $\sigma^{2}+\operatorname{chr} \sigma_{\mathrm{BP}(\mathrm{A})}^{2}+\operatorname{chpr} \sigma_{\mathrm{BA}}^{2}+\operatorname{chbr} \sigma_{\mathrm{P}(\mathrm{A})}^{2}+\operatorname{chbpr} \sigma_{\mathrm{A}}^{2}$ \\
\hline Plants (P)/A & 21 & $\sigma^{2}+\operatorname{chr}_{\mathrm{BP}(\mathrm{A})}{ }^{2}+\operatorname{chbr} \sigma_{\mathrm{P}(\mathrm{A})}{ }^{2}$ \\
\hline Blocks $(\mathrm{R}) / \mathrm{C}$ & 6 & $\sigma^{2}+h b a p \sigma_{R(C)}^{2}$ \\
\hline Bands (B) & 10 & $\sigma^{2}+\operatorname{chr} \sigma_{\mathrm{BP}(\mathrm{A})}^{2}+\operatorname{chpr} \sigma_{\mathrm{BA}}{ }^{2}+\operatorname{chapr}_{\mathrm{B}}{ }^{2}$ \\
\hline $\mathrm{C} \times \mathrm{B}$ & 10 & $\sigma^{2}+\operatorname{hapr} \sigma_{\mathrm{CB}}^{2}$ \\
\hline $\mathrm{C} \times \mathrm{A}$ & 2 & $\sigma^{2}+\operatorname{hbr} \sigma_{\mathrm{CP}(\mathrm{A})}^{2}+\operatorname{hbpr} \sigma_{\mathrm{CA}}{ }^{2}$ \\
\hline $\mathrm{C} \times \mathrm{P} / \mathrm{A}$ & 21 & $\sigma^{2}+h b r \sigma_{\mathrm{CP}(\mathrm{A})}$ \\
\hline $\mathrm{B} \times \mathrm{H} / \mathrm{C}$ & 20 & $\sigma^{2}+\operatorname{apr}_{\mathrm{BH}(\mathrm{C})}^{2}$ \\
\hline $\mathrm{B} \times \mathrm{A}$ & 7 & $\sigma^{2}+\operatorname{chr} \sigma_{\mathrm{BP}(\mathrm{A})}^{2}+\operatorname{chpr} \sigma_{\mathrm{BA}}{ }^{2}$ \\
\hline $\mathrm{B} \times \mathrm{P} / \mathrm{A}$ & 59 & $\sigma^{2}+\operatorname{chr} \sigma_{\mathrm{BP}(\mathrm{A})}$ \\
\hline $\mathrm{A} \times \mathrm{H} / \mathrm{C}$ & 4 & $\sigma^{2}+b r \sigma_{\mathrm{H}(\mathrm{C}) \mathrm{P}(\mathrm{A})}{ }^{2}+\mathrm{brp} \sigma_{\mathrm{AH}(\mathrm{C})}{ }^{2}$ \\
\hline $\mathrm{H} / \mathrm{C} \times \mathrm{P} / \mathrm{A}$ & 42 & $\sigma^{2}+b r \sigma_{H(C) P(A)}$ \\
\hline Error & $5866^{2}$ & $\sigma^{2}$ \\
\hline
\end{tabular}

${ }^{\bar{z}}$ Angle of dominant shoot and percentage of unserrated leaves degrees of freedom were 5812 and 5758, respectively, due to missing data.

Table 3. Estimated variance components (percentage of total variation) for three growth indexes (ANG, HT, and TSL) ${ }^{\mathrm{z}}$ of 'Foster' holly.

\begin{tabular}{lccc}
\hline \hline Component & ANG & HT & TSL \\
\hline Cycle (C) & $0^{\mathrm{ns}}$ & $11.8(8.1)^{* *}$ & $23(4.3)^{*}$ \\
Phase (H)/C & $48.3(8.9)^{* *}$ & $27.2(18.5)^{* *}$ & $171.7(32.2)^{* *}$ \\
Age group (A) & $0.75(0.1)^{\mathrm{NS}}$ & $0.2(0.1)^{\mathrm{NS}}$ & $1.6(0.3)^{\mathrm{NS}}$ \\
Block (R) & $0.9(0.2)^{*}$ & $0.7(0.5)^{* *}$ & $1.7(0.3)^{* *}$ \\
Plant (P)/A & $2.0(0.4)^{*}$ & $0.6(0.4)^{*}$ & $2.7(0.5)^{* *}$ \\
Band (B) & $0^{\mathrm{NS}}$ & $0.9(0.6)^{* *}$ & $3.6(0.7)^{*}$ \\
$\mathrm{C} \times \mathrm{B}$ & $4.0(0.70)^{* *}$ & $0^{\mathrm{NS}}$ & $1.1(0.2)^{\mathrm{NS}}$ \\
$\mathrm{C} \times \mathrm{A}$ & $2.54(0.5)^{*}$ & $0^{\mathrm{NS}}$ & $0.3(0.1)^{\mathrm{NS}}$ \\
$\mathrm{C} \times \mathrm{P}$ & $0.3(0.1)^{\mathrm{NS}}$ & $0.8(0.5)^{* *}$ & $2.1(0.4)^{*}$ \\
$\mathrm{~B} \times \mathrm{H}$ & $0.45(0.1)^{\mathrm{NS}}$ & $0.3(0.2)^{\mathrm{NS}}$ & $0^{\mathrm{NS}}$ \\
$\mathrm{B} \times \mathrm{A}$ & $1.43(0.3)^{\mathrm{NS}}$ & $0^{\mathrm{Ns}}$ & $0^{\mathrm{NS}}$ \\
$\mathrm{B} \times \mathrm{P}(\mathrm{A})$ & $0^{\mathrm{NS}}$ & $0.7(0.5)^{*}$ & $2.1(0.4)^{*}$ \\
$\mathrm{~A} \times \mathrm{H}(\mathrm{C})$ & $0^{\mathrm{NS}}$ & $0.7(0.5)^{*}$ & $0^{\mathrm{NS}}$ \\
$\mathrm{H}(\mathrm{C}) \times \mathrm{P}(\mathrm{A})$ & $0^{\mathrm{NS}}$ & $0.8(0.5)^{*}$ & $0^{\mathrm{NS}}$ \\
Error & $484.9(88.7)$ & $103.1(70.1)$ & $322.4(60.6)$ \\
$\mathrm{CV}$ & 37.47 & 40.16 & 40.36 \\
\hline
\end{tabular}

$\overline{{ }^{\mathrm{z}} \mathrm{ANG}}=$ angle of dominant shoot, $\mathrm{HT}=$ length of dominant shoot, and TSL $=$ sum of lengths of all shoots.

Ns,*,** Nonsignificant or significant at $P \leq 0.05$ or 0.01 , respectively. were fixed effects. Bands were not considered to be a fixed effect because the propagation histories of the 24 donor plants are presumably quite diverse and the number of bands per plant varies with plant age and height. The number of growth cycles away from the original ortet for any particular band was unknown. Bands in older plants would also have gone through more horizontal flushes, therefore, cuttings sampled on band 1 of a 2-year-old plant would be much different from cuttings on band 1 of a 20 -year-old plant. Since the number of meristem flushes has been associated with changes in maturation (Hackett, 1985), bands with the same number would not be equal.

Data were subjected to analysis of variance (ANOVA) and regression analysis (SAS Institute, 1987). Variance components were calculated by equating observed to expected mean squares and solving the resulting equations. Synthetic F tests were calculated by the procedure of Cochran (1951).

The magnitude of tested sources of variation was estimated by calculating the percentage of total variance contributed by the main effects and their two-way interactions for six growth indexes.

\section{Results}

ANG was not significantly affected by or correlated with stock plant age or crown position (band) where cuttings originated (Table 3). Statistical differences occurred between plants within age groups and among blocks. Error accounted for $89 \%$ of the variation in ANG, while all of the main effects and interactions accounted for $11 \%$ of differences (Table 3 ). Secondary propagation (cycles) did not affect angle (Table 3), but pruning (phase 2 of each cycle) significantly reduced ANG (Tables 3, 4, and 5). Increases in HT, TSL, SHN, NDS, and PUL showed a small but highly significant negative correlation with ANG (Table 6). When these indexes increased, ANG was reduced.

HT decreased significantly as the cutting site moved from the lower to upper crown (Table 5). Neither age group nor block affected HT, while plants/age group had significant growth differences.

Cycle exerted a highly significant effect on height differences (Tables 3 and 5), since taller dominant shoots were produced in cycle 1 than cycle 2 (Table 4 ). There was also a significant difference between phases within cycles (Table 3), with a trend of increasing mean HT from phase 1 to phase 2 (Table 5). Cycle 1, phase 2 (Table 4) accounts for much of this variation, since these shoots were 9 to $10 \mathrm{~cm}$ longer than those from other phases.

HT was negatively correlated with ANG but positively correlated with increases in TSL, SHN, NDS, and PUL (Table 6).

Table 4. Means by production cycle and phases within cycles for six growth indexes (ANG, HT, TSL, SHN, NDS, and PUL) ${ }^{\mathrm{z}}$ of 'Foster' holly.'

\begin{tabular}{|c|c|c|c|c|c|c|c|}
\hline Cycle & Phase & ANG & HT & TSL & SHN & NDS & PUL \\
\hline 1 & & 58 & 27.6 & 41.4 & 2.8 & 17.6 & 5.2 \\
\hline 2 & & 60 & 22.4 & 48.3 & 3.9 & 16.6 & 3.9 \\
\hline \multicolumn{8}{|c|}{ Cycle 1} \\
\hline & 1 & 65 & 23.3 & 30.3 & 2.1 & 15.6 & 4.8 \\
\hline & 2 & 51 & 32.1 & 52.9 & 3.6 & 19.8 & 5.6 \\
\hline \multicolumn{8}{|c|}{ Cycle 2} \\
\hline & 1 & 59 & 22.8 & 43.2 & 2.9 & 16.7 & 5.0 \\
\hline & 2 & 61 & 22.0 & 53.6 & 4.9 & 16.4 & 2.8 \\
\hline
\end{tabular}

${ }^{\mathrm{z}} \mathrm{ANG}=$ angle of dominant shoot, $\mathrm{HT}=$ length of dominant shoot, $\mathrm{TSL}=$ sum of lengths of all shoots, $\mathrm{SHN}=$ total number of shoots, $\mathrm{NDS}=$ number of nodes on the dominant shoot, and PUL $=$ percentage of unserrated leaves.

yStatistical tests are reported in Tables 3 and 8. 
Table 5. Coefficients for correlations between main effects in the analysis of variance model (age, cycle, phase, and band) and six growth indexes (ANG, HT, TSL, SHN, NDS, and PUL) ${ }^{\mathrm{Z}}$.

\begin{tabular}{|c|c|c|c|c|c|c|}
\hline Main effect & ANG & HT & TSL & SHN & NDS & PUL \\
\hline$\overline{\text { Age }}$ & $0.01^{\mathrm{NS}}$ & $-0.01^{\mathrm{NS}}$ & $-0.01^{\mathrm{NS}}$ & $-0.02^{\mathrm{NS}}$ & $-0.01^{\mathrm{NS}}$ & $-0.00^{\mathrm{NS}}$ \\
\hline Cycle & $0.04^{* *}$ & $-0.23^{* *}$ & $0.17^{* *}$ & $0.33^{* *}$ & $-0.07^{* *}$ & $-0.09^{* *}$ \\
\hline Phase & $-0.14^{* *}$ & $0.20^{* *}$ & $0.42^{* * *}$ & $0.53^{* *}$ & $0.15^{* * *}$ & $-0.04^{* *}$ \\
\hline Band & $0.02^{\mathrm{NS}}$ & $-0.05^{* *}$ & $-0.06^{* *}$ & $-0.02^{\mathrm{NS}}$ & $-0.04^{* *}$ & $0.00^{\mathrm{NS}}$ \\
\hline
\end{tabular}

${ }^{\mathrm{z}} \mathrm{ANG}=$ angle of dominant shoot, $\mathrm{HT}=$ length of dominant shoot, $\mathrm{TSL}=$ sum of lengths of all shoots, $\mathrm{SHN}=$ total number of shoots, $\mathrm{NDS}=$ number of nodes on the dominant shoot, and PUL $=$ percentage of unserrated leaves.

Ns,*,*** Nonsignificant or significant at $P \leq 0.05$ or 0.01 , respectively.

Table 6. Correlations between six growth indexes (ANG, HT, TSL, SHN, NDS, and PUL) $)^{\mathrm{z}}$ used to measure propagules of 'Foster' holly.

\begin{tabular}{lcrrrr}
\hline \hline & HT & TSL & \multicolumn{1}{c}{ SHN } & \multicolumn{1}{c}{ NDS } & \multicolumn{1}{c}{ PUL } \\
\hline ANG & $-0.13^{* *}$ & $-0.11^{* *}$ & $-0.06^{* * *}$ & $-0.12^{* *}$ & $-0.05^{* *}$ \\
HT & & $0.65^{* *}$ & $0.06^{* *}$ & $0.90^{* *}$ & $0.08^{* *}$ \\
TSL & & & $0.61^{* *}$ & $0.26^{* *}$ & $0.02^{\text {NS }}$ \\
SHN & & & & $0.07^{* *}$ & $-0.03^{*}$ \\
NDS & & & & & $0.04^{* *}$ \\
\hline
\end{tabular}

${ }^{\mathrm{z}} \mathrm{ANG}=$ angle of dominant shoot, $\mathrm{HT}=$ length of dominant shoot, $\mathrm{TSL}=$ sum of lengths of all shoots, $\mathrm{SHN}=$ total number of shoots, $\mathrm{NDS}=$ number of nodes on the dominant shoot, and PUL = percentage of unserrated leaves.

Ns, ${ }^{* * *}$ Nonsignificant or significant at $P \leq 0.05$ or 0.01 , respectively.

Comparison between the four growth phases by correlation in Table 7 revealed that cycle 1, phase 1 (HT11) showed a small but significant correlation with cycle 1, phase 2 (HT12) and a negative correlation with cycle 2, phase 1 (HT 21). Cycle 2, phase 1 (HT 21) showed a moderately large significant correlation with cycle 2 , phase 2 (HT 22).

The significant main effects accounting for the greatest percentage of variation in HT are phase/cycle (19\%) and cycle $(8 \%)$, whereas bands, plants/age, and blocks accounted for $\approx 0.5 \%$ each (Table 3 ). Three two-way interactions were significant and collectively accounted for $1.5 \%$ of the variance. Residual accounted for $70 \%$ of the variance.

TSL was significantly affected by the band where cuttings originated (Table 3). Correlation (Table 5) between band number and TSL was small but significant, with a negative value, indicative of decreased TSL as bands moved up the plant. Age group had no detectable effect on TSL, while blocks were significantly different (Table 3). Plants/age group were significantly different, a result indicating environmental effects independent of maturation.

Cycle and phase/cycle were also significantly different for TSL (Table 3). Both were positively correlated with TSL, with phase showing a much stronger correlation than cycle (Table 5). Mean TSL increased from cycle 1 to cycle 2 , but a much larger increase in mean shoot growth occurred from phase 1 to phase 2 in each cycle (Table 4).

TSL was positively correlated with HT, SHN, and NDS but negatively correlated with ANG (Table 6). Comparison between the four growth phases revealed that cycle 1, phase 1 (TSL 11) was positively correlated with cycle 1 , phase 2 (TSL 12) but negatively correlated with cycle 2 , phase 1 (TSL 21) and cycle 2 , phase 2 (TSL 22) (Table 7). The correlation between TSL 21 and TSL 22 was the strongest of the associative comparisons between phases.

Phase/cycle accounted for $32 \%$ of the total variance among TSL data, while the sum of the other five main effects was only $6 \%$. Significant two-way interactions accounted for $0.8 \%$ and residual accounted for $61 \%$ of the variation (Table 3 ).

SHN was not affected by band, age group, or plants/age group where cuttings originated. Significant differences in SHN were indicated among blocks, cycles, and phase/cycle (Table 8). Cycle and phase/cycle were positively correlated with SHN (Table 6), a result indicating increased shoots from cycle 1 to cycle 2 and from phase 1 to phase 2 within each cycle (Table 4 ).

SHN was strongly correlated with TSL and NDS, negatively correlated with ANG, and weakly correlated with HT (Table 6). Comparison of the correlations for the four growth phases indicated moderately strong correlations between phases within cycles, but no correlations existed among cycles (Table 7).

NDS tended to decrease for cuttings collected from the upper crown (Tables 5 and 9). Stock plant age did not affect NDS, but there were significant differences for plants/age and blocks (Table $8)$. Mean NDS for age group 1 showed that the greatest variation, with mean from 14 to 20, while group 2 varied from 16 to 18 and

Table 7. Correlation within six growth indexes (ANG, HT, TSL, SHN, NDS, and PUL) ${ }^{\mathrm{Z}}$ during four stages of production [cycle 1, phase 1 (11) and phase 2 (12); cycle 2, phase 1 (21) and phase 2 (22)] for 'Foster' holly.

\begin{tabular}{|c|c|c|c|}
\hline & ANG12 & ANG21 & ANG22 \\
\hline$\overline{\text { ANG11 }}$ & $-0.05^{*}$ & $0.04^{\mathrm{NS}}$ & $0.01^{\mathrm{NS}}$ \\
\hline ANG12 & & $0.02^{\mathrm{NS}}$ & $-0.08^{* * *}$ \\
\hline \multirow[t]{2}{*}{ ANG21 } & & & $-0.03^{\mathrm{NS}}$ \\
\hline & HT12 & HT21 & HT22 \\
\hline HT11 & $0.08^{* * *}$ & $-0.22^{* *}$ & $-0.04^{\mathrm{NS}}$ \\
\hline HT12 & & $0.03^{\mathrm{NS}}$ & $-0.01^{\mathrm{NS}}$ \\
\hline \multirow[t]{2}{*}{ HT21 } & & & $0.28^{* *}$ \\
\hline & TSL12 & TSL21 & TSL22 \\
\hline TSL11 & $0.31^{* *}$ & $-0.17^{* *}$ & $-0.06^{*}$ \\
\hline TSL12 & & $-0.02^{\mathrm{NS}}$ & $-0.01^{\mathrm{NS}}$ \\
\hline \multirow[t]{2}{*}{ TSL21 } & & & $0.42^{* * *}$ \\
\hline & SHN12 & SHN21 & SHN22 \\
\hline SHN11 & $0.31^{* *}$ & $0.04^{\mathrm{NS}}$ & $0.02^{\mathrm{NS}}$ \\
\hline SHN12 & & $-0.01^{\mathrm{NS}}$ & $-0.03^{\mathrm{NS}}$ \\
\hline \multirow[t]{2}{*}{ SHN21 } & & & $0.31^{* *}$ \\
\hline & NDS12 & NDS21 & NDS22 \\
\hline NDS11 & $0.03^{\mathrm{NS}}$ & $-0.20^{* * *}$ & $-0.00^{\mathrm{NS}}$ \\
\hline NDS12 & & $0.03^{\mathrm{NS}}$ & $-0.03^{\mathrm{NS}}$ \\
\hline \multirow[t]{2}{*}{ NDS21 } & & & $0.26^{* *}$ \\
\hline & PUL12 & PUL21 & PUL22 \\
\hline PUL11 & $-0.01^{\mathrm{NS}}$ & $-0.01^{\mathrm{NS}}$ & $-0.05^{\mathrm{NS}}$ \\
\hline PUL12 & & $-0.01^{\mathrm{NS}}$ & $0.05^{\mathrm{NS}}$ \\
\hline PUL21 & & & $0.03^{\mathrm{NS}}$ \\
\hline
\end{tabular}

${ }^{\mathrm{z}} \mathrm{ANG}=$ angle of dominant shoot, $\mathrm{HT}=$ length of dominant shoot, $\mathrm{TSL}=$ sum of lengths of all shoots, $\mathrm{SHN}=$ total number of shoots, $\mathrm{NDS}=$ number of nodes on the dominant shoot, and PUL $=$ percentage of unserrated leaves.

Ns, *** Nonsignificant or significant at $P \leq 0.05$ or 0.01 , respectively. 
group 3 ranged from 17 to 18 .

NDS was significantly different between cycles (Table 8), with a small negative correlation (Table 5) reflecting the decrease in mean from cycle 1 to cycle 2 (Table 4 ). Phase/cycle was significantly different (Table 8), with a larger change in means between cycle 1 phases than cycle 2 phases (Table 4 ). Changes in NDS between cycles were positively correlated (Table 5).

NDS showed a strong positive correlation with HT and TSL and was weakly correlated with ANG, SHN, and PUL. The number of nodes for cycle 1, phase 1 (NDS11) was not linked to performance of phase 2 for either cycle (Table 7) but was negatively correlated with cycle 2 , phase 1 (NDS21). This indicated that the propagules (NDS21) had fewer nodes than their mother ramet (NDS11). Cycle 2 phases (NDS21 and NDS22) were positively correlated.

Phase/cycle accounted for $10 \%$ of total variance which was more than twice as large as that for the other main effects and two-way interactions combined (Table 8). Most of the variance $(86 \%)$ was accounted for by the error term.

PUL was significantly different among blocks and among plants/age group. Percentage of nonserrated leaves was also more variable than other indexes, as indicated by the 4-fold increase in the coefficient of variation (Table 8). Small but significant correlations of PUL with cycle, phase, ANG, HT, SHT, and NDS (Tables

Table 8. Estimated variance components (percentage of total variation) for three growth indexes (SHN, NDS, and PUL) ${ }^{\mathrm{z}}$ in 'Foster' holly.

\begin{tabular}{|c|c|c|c|}
\hline Component & SHN & NDS & PUL \\
\hline Cycle (C) & $0.7(19.1)^{k * *}$ & $0.67(1.1)^{*}$ & $1.25(1.8)^{\mathrm{NS}}$ \\
\hline Phase $(\mathrm{H}) / \mathrm{C}$ & $1.43(37.2)^{* *}$ & $6.2(10.4)^{* * *}$ & $2.14(3.1)^{\mathrm{NS}}$ \\
\hline Age group (A) & $0.01(0.3)^{\mathrm{NS}}$ & $0^{\mathrm{NS}}$ & $0^{\mathrm{NS}}$ \\
\hline Block (R) & $0.01(0.3)^{* * *}$ & $0.33(.6)^{* * *}$ & $1.3(1.9)^{* *}$ \\
\hline Plant (P)/A & $0.01(0.3)^{\mathrm{NS}}$ & $0.30(.5)^{*}$ & $0.32(0.5)^{* * *}$ \\
\hline Band (B) & $0^{\mathrm{NS}}$ & $0.37(.6)^{*}$ & $0.05(0.1)^{\mathrm{NS}}$ \\
\hline $\mathrm{C} \times \mathrm{B}$ & $0.01(0.3)^{*}$ & $0^{\mathrm{NS}}$ & $0.09(0.1)^{\mathrm{NS}}$ \\
\hline $\mathrm{C} \times \mathrm{A}$ & $0^{\mathrm{NS}}$ & $0^{\mathrm{NS}}$ & $0.09(0.1)^{\mathrm{NS}}$ \\
\hline $\mathrm{C} \times \mathrm{P}$ & $0.01(0.3)^{*}$ & $0.27(.5)^{*}$ & $0^{\mathrm{NS}}$ \\
\hline $\mathrm{B} \times \mathrm{H}$ & $0^{\mathrm{NS}}$ & $0^{\mathrm{NS}}$ & $0.32(0.5)^{*}$ \\
\hline $\mathrm{B} \times \mathrm{A}$ & $0.01(0.3)^{\mathrm{NS}}$ & $0^{\mathrm{NS}}$ & $0^{\mathrm{NS}}$ \\
\hline $\mathrm{B} \times \mathrm{P}(\mathrm{A})$ & $0.02(0.5)^{*}$ & $0.16(0.3)^{\mathrm{NS}}$ & $0^{\mathrm{NS}}$ \\
\hline $\mathrm{A} \times \mathrm{H}(\mathrm{C})$ & $0^{\mathrm{NS}}$ & $0^{\mathrm{NS}}$ & $0^{\mathrm{NS}}$ \\
\hline $\mathrm{H}(\mathrm{C}) \times \mathrm{P}(\mathrm{A})$ & $0^{\mathrm{NS}}$ & $0.28(0.5)^{\mathrm{NS}}$ & $1.3(1.9)^{\text {** }}$ \\
\hline Error & $1.6(41.4)$ & $51.2(85.5)$ & $62.4(90.0)$ \\
\hline $\mathrm{CV}$ & 38.10 & 41.70 & 172.11 \\
\hline
\end{tabular}

$\overline{{ }^{\mathrm{z}} \mathrm{SHN}}=$ total number of shoots, NDS = number of nodes on the dominant shoot, and PUL = percentage of unserrated leaves.

Ns,*,** Nonsignificant or significant at $P \leq 0.05$ or 0.01 , respectively.

Table 9. Regression models ${ }^{\mathrm{z}}$ for each of the six growth indexes (ANG, HT, TSL, SHN, NDS, and PUL) $)^{\mathrm{y}}$ used to characterize Foster holly.

\begin{tabular}{lc}
\hline \hline ANG & NS \\
HT $=1.75+1.37 \mathrm{NDS}$ & $R^{2}=0.80$ \\
TSL $=-8.35+1.15 \mathrm{HT}+7.22 \mathrm{SHN}$ & $R^{2}=0.73$ \\
SHN $=2.13-0.09 \mathrm{HT}+0.08 \mathrm{TSL}$ & $R^{2}=0.56$ \\
NDS $=2.40+0.59 \mathrm{HT}$ & $R^{2}=0.80$ \\
PUL & NS
\end{tabular}

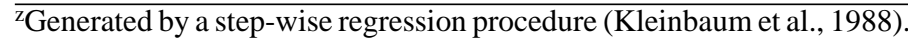
${ }^{\mathrm{y}} \mathrm{ANG}=$ angle of dominant shoot, $\mathrm{HT}=$ length of dominant shoot, $\mathrm{TSL}=$ sum of lengths of all shoots, $\mathrm{SHN}=$ total number of shoots, $\mathrm{NDS}=$ number of nodes on the dominant shoot, and PUL $=$ percentage of unserrated leaves.

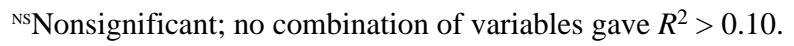

5 and 6) were indicated, but no correlations occurred for PUL between phases when two-way comparisons of different phases were calculated (Table 7). Error accounted for $90 \%$ of variation among PUL readings, with main effects and two-way interactions accounting for $7 \%$ and $3 \%$, respectively. Significant main effects for blocks/cycle and plants/age group were indicative of environmental sensitivity. Likewise, significant interactions for band $\times$ phase/cycle and phase/cycle $\times$ plants/age group also indicated environmental sensitivity of the index.

\section{Discussion}

Our results indicate that intra-clonal variation was present in stem cuttings of 'Foster' holly collected from ramets that varied in age and cultural environment. Phase/cycle, block/cycle, and plants/ age group were designed to partition short-term environmental effects on cutting development, while cycle, age group, and band tested for variation generally associated with maturation. Both types of variation were detected. Such variation could have adverse effects on production programs designed to maximize crop uniformity and reduce cropping time.

Scott (1987) reported that when each cultivar in a stock area was propagated from a single parent source, uniformity of plant growth was enhanced, but she did not quantify or specify reasons for the improvement. Some changes within adult plants result from stable changes in the apical meristem that are confounded with the effects of increasing size and complexity. Changes in the meristem associated with maturation are stable, while the confounding factors can be reversed by vegetative propagation (Wareing, 1959).

Ilex $\times$ attenuata seedlings generally flower within 3 to 5 years after germination. Brink (1962) used this trait to mark the transition from juvenility to maturity. Flowering is only one of many aspects of the general phenomenon of maturation and a better concept would summarize changes that occur (Bonga, 1982; Dunberg, 1977; Franclet, 1983) with increasing plant size, complexity, and age. 'Foster' holly acquires a pendulous branching habit when plants are $\approx 15$ years old, a trait generally associated with maturation (Schaffalizky de Muckadell, 1959). Rooting potential, a juvenile characteristic (Hackett, 1988), is high for 'Foster' holly (Dirr, 1983). Entire leaves are randomly intermixed with normally serrated leaves. Change from serrate to entire leaves is associated with maturation in several oriental species of Ilex such as I. cornuta Lindl. \& Paxton (Gene Eisenbeiss, U.S. National Arboretum, personal communication).

Observations of 'Foster' holly grown under many cultural and climatic conditions revealed that young propagules exhibit a wide spectrum of stem angles. Some are vertical but most are nonvertical to varying degrees. Since few, if any, growers are concerned with intra-clonal variations, we theorized that part of the variation may be due to cyclophysis (age effects). Partitioning variation due to age and crown position (band) as expressed by ANG of young plants revealed no link between the factors and poor stem angle (Table 3).

Secondary propagation (cycle 2) was used to test whether cuttings generated from plants growing under uniform cultural conditions had less variation in $\mathrm{ANG}$ than cuttings randomly collected from multiple environments (cycle 1). By correlating stock plants (cycle 1) and their propagules (cycle 2), an evaluation could also be made to determine if ANG of plant affected ANG of propagule. Neither repropagation nor parent plant affected ANG of young plants in cycle 2 (Table 7).

Several minor factors decreased the vertical orientation of the 
main shoot of young 'Foster' holly. Regrowth after heavy pruning (phase 2 of each cycle) tended to decrease the vertical orientation of plants. Correlations also indicated that when plants were larger (greater HT, TSL, SHN, and NDS), the orientation of the dominant stem was less vertical. There was also a greater reduction in mean ANG after pruning (phase 1 vs. phase 2) in propagules from various environments (cycle 1) than in repropagated material (cycle 2).

Percentage of unserrated leaves (PUL) was highly variable and not affected by stock plant age or crown position where propagules originated. Variation in leaf serration is apparently not a stable change associated with maturation in this clone. Instead, leaf serration is primarily linked to environmental changes.

Intra-clonal changes in growth indexes, such as HT, TSL, SHN, and NDS, were better indicators of intra-clonal changes than ANG or PUL. The four traits are highly correlated measures of growth (Table 9).

None of the four growth indexes was affected by the age of the 'Foster' holly ramet where propagules originated. There were, however, differences between plants within age groups for HT, TSL, and NDS. Physiological differences due to environmental influences on individual donor plants within age groups, carried forward in propagules, seem to be the primary cause of the observed intra-clonal variation within age groups.

Crown position (band) had no effect on SHN, but there was a trend to lower HT, TSL, and NDS as the cutting site moved from the base of ramets up the crown (Table 5). Other researchers have reported that crown position affects propagule leaf retention (Schaffalitzky de Muckadell, 1959), rooting potential (Roulund, 1973), thorniness (Soost and Cameron, 1975), and plant form (Roulund, 1979) in other genera. In this study, reductions in growth indexes were associated with the distance from the roots of the cutting site where propagules were collected but not with the chronological age of the ramet.

Repropagation (cycle 1 vs. cycle 2) resulted in significant changes in all four growth indexes (Table 4). In cycle 2, HT and NDS decreased, whereas means for TSL and SHN increased. Improvement in TSL and SHN after repropagation is consistent with growth changes following repropagation observed by others in a variety of genera (Black, 1972; Boulay, 1979; Franclet, 1979; Ooyama and Toyoshima, 1965). Rapid improvement in a character after repropagation would be consistent with Wareing's (1959) definition of improvement due to physiological changes (invigoration), as contrasted with changes in a maturation-related characteristic (rejuvenation).

Another interesting observation was the negative correlation detected for HT, TSL, and NDS between cycle 1, phase 1 and cycle 2 , phase 1 (Table 7). Comparison of index means for phase 1 of both cycles shows HT to be about the same, while HT and NDS means improved in cycle 2 (Table 4 ). The negative correlations thus indicate that there was a general trend for propagules that were large in cycle 1 to be smaller in cycle 2 , whereas propagules from smaller plants in cycle 1 produced larger plants in cycle 2 . One hypothesis for such changes in growth after repropagation may be found in observations on I. crenata Thunb. 'Helleri' that indicated that growth flushes in this cultivar were preceded by accumulation of mineral nutrient reserves to a critical level (Gilliam and Wright, 1978). If taller plants in cycle 1 were the result of growth flushes that depleted nutrient reserves while short plants retained higher reserves in preparation for growth, then such differences could be reflected in corresponding changes in cycle 2.

Most variation among 'Foster' holly propagules was not accounted for by main effects or two-way interactions in the ANOVA
(Tables 3 and 8). Most of the intra-clonal variation observed in 'Foster' holly in this study originated from unspecified sources. Other than small differences in HT, TSL, and NDS associated with origin of the cuttings in the crown, repropagation gave no indication of variation originating from factors measured by our model that could be passed from ramet to propagule as in $\mathrm{m}$ effects (Burdon and Shelbourne, 1974) or epigenetic variation (Kester, 1983). Intra-clonal variation was not reduced by repropagation or by cutting back propagules to force new growth.

\section{Literature Cited}

Ashby, E. 1949. Leaf shape. Sci. Amer. 181:22-24.

Black, D.K. 1972. The influence of shoot origin on the rooting of Douglas-fir stem cuttings. Proc. Intl. Plant Prop. Soc. 22:142-159.

Blake, T.J. and W.S. Filho. 1988. Drought tolerance, growth partitioning and vigor in eucalypt seedlings and rooted cuttings. Tree Physiol. 4:325335 .

Bonga, J.M. 1982. Vegetative propagation in relation to juvenility, maturity, and rejuvenation, p. 387-412. In: J.M. Bonga and D.J. Durzan (eds.). Tissue culture in forestry. Martinus Nijhoff Publ., Dordrecht, Netherlands.

Boulay, M. 1979. Micropropagation d'arbres forestiers. Assn. Foret-Celulose, Nagis, France. p. 49-56.

Brink, R.A. 1962. Phase change in higher plants and somatic cell heredity. Quarterly Rev. Biol. 37:1-22.

Burdon, R.D. and C.J. Shelbourne. 1974. The use of vegetative propagules for obtaining genetic information. N.Z. J. For. Sci. 4:418-425.

Cannell, M.G., F.E. Bridgwater, and M.S. Greenwood. 1978. Seedling growth rates, water stress responses and root-shoot relationships related to eight-year volumes among families of Pinus taeda L. Silvae Genet. 27:237-246.

Cochran, W.G. 1951. Testing a linear relation among variances. Biometrics 7:17-32.

Dirr, M.A. 1983. Manual of woody landscape plants: Their identification, ornamental characteristics, culture, propagation and uses. Stipes Publishing Co., Champaign, Ill.

Dunberg, A. 1977. Vegetative propagation of forest trees-Physiology and practice. Inst. For. Improvement and Dept. For. Genetics, Swedish Univ. Agr. Sci., Uppsala, Sweden.

Foster, G.S., R.K. Campbell, and W.T. Adams. 1984. Heritability, gain, and $C$ effects in rooting of western hemlock cuttings. Can. J. For. Res. 14:628-648.

Franclet, A. 1979. Micropropagation d'arbres forestiers. Assn. Foret-Cellulose, Nangis, France. p. 3018.

Franclet, A. 1983. Rejuvenation: Theory and practical experience in clonal silviculture, p. 96-134. In: L. Zsuffa, R.M. Rauter and C.W. Yeatman (eds.). Clonal forestry: Its impact on tree improvement and our future forests. Proc. Can. Tree Improvement Assn. 19th meeting part II. Galle, F. 1970. Hollies native to the United States. Amer. Hort. Mag. 49(4):180-192.

Gilliam, C.H. and R.D. Wright. 1978. Timing of fertilizer applications in relation to growth flushes of 'Helleri' holly (Ilex crenata Thunb.). HortScience 13:300-301.

Hackett, W.P. 1983. Phase change and intra-clonal variability. HortScience 18:840-844.

Hackett, W.P. 1985. Juvenility, maturation, and rejuvenation in woody plants. Hort. Rev. 7:109-155.

Hackett, W.P. 1988. Donor plant maturation and adventitious root formation, p. 11-28. In: T.D. Davis, B., E. Haissig, and N. Sankhla (eds.). Adventitious root formation in cuttings. Dioscoroides Press, Portland, Ore.

Kester, D.E. 1983. The clone in horticulture. HortScience 18:3-9.

Kleinbaum, D. G., L.L. Kupper, and K.E. Muller. 1988. Applied regression analysis and other multivariable methods. PWS-Kent Publishing Co., Boston.

Lerner, I.M. 1958. The genetic basis of selection. Wiley, New York.

Libby, W.J. 1974. The use of vegetative propagules in forest genetics and tree improvement research. N.Z. J. For. Sci. 4:440-447. 
Libby, W.J. and J.V. Hood. 1976. Juvenility in hedged radiata pine. Acta Hort. 56:91-98.

Libby, W.J. and E. Jund. 1962. Variance associated with cloning. Heredity 17:533-540.

Olesen, P.O. 1978. On cyclophysis and topophysis. Silvae Genet. 27:173178.

Ooyama, N. and A. Toyoshima. 1965. Rooting ability of pine cuttings and its promotion. Bul. Govt. For. Expt. (Tokyo) 179:100-25.

Roulund, H. 1973. The effect of cyclophysis and topophysis on the rooting ability of Norway spruce cuttings. For. Tree Improvement 5:21-41.

Roulund, H. 1979. Stem form of cuttings related to age of ortets and position of scions. (Picea abies (L.) Karst.) For. Tree Improvement 13:1-24.
SAS Institute. 1987. SAS/STAT guide for personal computers. version 6. SAS Institute, Cary, N.C.

Schaffalitzky de Muckadell, M. 1959. Investigations on aging of apical meristems in woody plants and its importance in silviculture. Forstlige forsøgsvaesen Danmark 25:310-455.

Scott, M.A. 1987. Management of hardy nursery stock plants to achieve high yields of quality cuttings. HortScience 22:738-741.

Soost, R.K. and J.W. Cameron. 1975. Citrus, p. 507-540. In: J.N. Moore and J. Janick (eds.). Advances in fruit breeding. Purdue Univ. Press, West Lafayette, Ind.

Wareing, P.F. 1959. Problems of juvenility and flowering in trees. J. Lenin Soc. Bot. 56:282-289.

Zobel, B. and J. Talbert. 1984. Applied forest tree improvement. Wiley, New York. 